\title{
PETRÓLEO Y SOBERANİA ENERGÉTICA EN BRASIL
}

\author{
Gilberto Bercovici \\ Profesor Catedrático de Derecho Económico y Economía Política \\ Universidad de São Paulo
}

Recepción: 8 de enero de 2015

Aprobado por el Consejo de redacción: 2 de marzo de 2015

RESUMEN: El estudio del ordenamiento jurídico brasileño permite visualizar la importancia de los recursos naturales como elementos estratégicos para la estructuración de la economía. Los recursos minerales $y$, particularmente, el petróleo, se configuran históricamente como objeto de disputa entre los distintos grupos de poder. La previsión constitucional del monopolio estatal del petróleo constituye, así, una estrategia fundamental para la preservación de la soberanía energética.

PALABRAS CLAVE: Petróleo; Soberanía energética; Privatizaciones; Monopolio estatal.

ABSTRACT: The study of the Brazilian legal system allows us to visualize the importance of natural resources and consider them as strategic elements for the structuring of the economy. Mineral resources and, specially, petroleum are set historically as an object of dispute among the different power groups. In this way, the constitutional prevision of the state monopoly of petroleum constitutes a fundamental strategy to the maintenance of the energetic sovereign.

KEYWORDS: Petroleum; Energetic sovereign; Privatizations; State monopoly. 
El control nacional sobre los recursos naturales estratégicos, particularmente los recursos minerales y el petróleo, también deriva de la idea de soberanía económica. La disputa sobre el mantenimiento de la nacionalización del subsuelo o el favorecimiento al capital extranjero en el sector de minería fue intensa durante la Asamblea Nacional Constituyente 1 . La Constitución de 1988, al determinar que la propiedad del subsuelo y de los bienes minerales es de la Unión (artículos 20, IX e 176, caput), consagra el proceso de nacionalización del subsuelo iniciado en $1934^{2}$.

La soberanía energética es un componente esencial de la soberanía económica nacional, pues abarca un sector clave de la economía del país. El Estado debe tomar decisiones autónomas sobre la producción y destino de sus recursos energéticos, planeando su desarrollo y evitando la dependencia tecnológica de factores externos para la producción de energía. De este modo, el control estatal sobre las fuentes de energía consiste en un eje central de un proyecto democrático en el que la política macroeconómica esté al servicio de los intereses nacionales, además de poder propiciar un planeamiento energético a largo plazo ${ }^{3}$.

Visando garantizar esta soberanía energética, la constitucionalización del monopolio del petróleo fue mantenida y ampliada por la Asamblea Nacional Constituyente de 19871988. Durante los trabajos de la Asamblea, se llegó, inclusive, a proponer la monopolización de la distribución de los derivados del petróleo, permitiéndose, sin embargo, la concesión a empresas privadas con mayoría de capital nacional. No obstante, la articulación de los sectores conservadores en el llamado "Centrão" consiguió retirar el monopolio estatal de la distribución de los derivados de petróleo del texto en la votación en primer turno del proyecto de constitución. A pesar de la retirada de la distribución de derivados, todas las demás actividades componentes del monopolio estatal del petróleo fueron mantenidas, así como el monopolio sobre el gas natural. A demás de esto, reaccionando a la política de los contratos de riesgo del régimen militar, la Asamblea Nacional Constituyente prohibió expresamente la realización de nuevos contratos de esta naturaleza ${ }^{4}$.

1 DUARTE (1988), pp. 99-169; PILATTI, (2008), pp. 246-249, 259-260 y 295-298.

2 RIBEIRO (1989) p. 70; ALBINO (2002) pp. 121-123, 465-466 y 500-501.

3 BERNAL (2005) p. 31; FEROLLA \&t METRI (2006) pp. 23-25 y 77-87.

4 Artículo 177 de la Constitución de 1988 (redacción original): "Constituyen monopolio de la Unión: I - la búsqueda y extracción de los yacimientos de petróleo y gas natural y otros hidrocarburos fluidos; Il - el refinamiento del petróleo nacional o extranjero; III - la importación y exportación de los productos y derivados básicos resultantes de las actividades previstas en los incisos anteriores; IV - el transporte maritimo del petróleo bruto de origen nacional o de derivados básicos de petróleo producidos en el Pais, como asi el transporte, por medio de conducto, de petróleo bruto, sus derivados y gas natural de cualquier origen; V - la búsqueda, la extracción, el enriquecimiento, y reprocesamiento, la industrialización y el comercio de minerales nucleares y sus derivados. \$1 ${ }^{\circ}-$ El monopolio previsto en este artículo incluye los riesgos e resultados derivados de las actividades en él mencionadas, siendo vedado a la Unión ceder o conceder cualquier tipo de participación, en especie o en valor, en la explotación de yacimientos de petróleo o gas natural, salvo lo dispuesto en el art. $20, \S 1^{\circ}$. $2^{\circ}$ - La ley dispondrá sobre el transporte y la utilización de materiales radioactivos en el territorio nacional". Véase, también, PILATTI, Adriano (2008) A Constituinte de 1987-1988: Progressistas, Conservadores, Ordem Econômica e Regras do Jogo (Rio de Janeiro, Ed. PUC-Rio/Lumen Juris) pp. 180-181, 261-263 y 298-299 y ALBINO DE SOUZA Washington (2002) Teoria da Constituição Econômica 
El monopolio de la Unión en la explotación y refinamiento del petróleo extiende, sin embargo, sus efectos a los derivados del petróleo. La autorización, regulación y control de la venta y distribución de combustibles derivados del petróleo, inclusive el gas natural, alcohol carburante y los combustibles derivados de materias primas renovables, según el artículo 238 de la Constitución de 1988, serian definidos por la ley federal ${ }^{5}$. Hasta 1990, el órgano responsable era el Consejo Nacional del Petróleo, sucedido, a partir de entonces, por el Departamento Nacional de Combustibles (artículo 222 del Decreto no 99.244, de 10 de mayo de 1990) ${ }^{6}$. Aún en relación a la explotación del petróleo, la Constitución de 1988 mantuvo la garantía de funcionamiento de las refinerías privadas existentes antes de la aprobación de la Ley no 2.004/1953, de acuerdo con el artículo 45 del Acto de las Disposiciones Constitucionales Transitorias?.

La Petrobras seria combatida desde el Gobierno de Fernando Collor de Mello, con políticas que pretendian reducir su dimensión económica y, como corolario, proponiendo el fin del monopolio estatal del petróleo y la propia privatización de la empresa. Varias subsidiarias de la Petrobras fueron privatizadas, como la Interbras y la Petromisa, además de la Fosfértil y otras subsidiarias del sector de fertilizantes, y de la venta de participaciones de la Petrobras y de la subsidiaria Petroquisa en varios emprendimientos de la industria petroquímica ${ }^{8}$.

El Consejo Nacional del Petróleo fue extinto en 1990, siendo substituido por el Departamento Nacional de Combustibles (DNC), vinculado al Ministerio de Minas y Energía. La política nacional de abastecimiento de combustibles, antes prevista por el Decreto $n^{\circ}$ 49.331, de 24 de noviembre de 1960 (derogado por el Decreto n 99.432, de 31 de julio de 1990), fue modificada en el sentido de liberar los precios de los combustibles y los márgenes de distribución y reventa, excluyendo la exigencia de volúmenes mínimos de comercialización por distribuidora y la obligatoriedad de comercialización en el punto de reventa de los productos fornecidos por la distribuidora de la misma marca (esta última medida revisada, posteriormente, por la Agencia Nacional del Petróleo). Con el Plan Real, la importación de derivados del petróleo fue liberada, así como fue garantizado el libre acceso a oleoductos, tanques y terminales, además de haber sido extinto el mecanismo de actualización de los precios al consumidor en todo el país. El resultado fue la ampliación de las empresas distribuidoras, como era pretendido, pero también la diseminación de las

(Belo Horizonte, Del Rey) pp. 464-465.

5 Artículo 238 de la Constitución de 1988: "La ley ordenará la venta y reventa de combustibles de petróleo, alcohol carburante y otros combustibles derivados de materias primas renovables, respetados los principios de esta Constitución".

6 TÁCITO (1997) pp. 1128-1130; KONDER (1996) p. 152; VALOIS (2000) pp. 137-139.

7 Artículo 45 del Acto de las Disposiciones Constitucionales Transitorias: "Quedan excluidas del monopolio establecido por el art. 177, II, de la Constitución las refinerías en funcionamiento en el País amparadas por el art. 43 y en las condiciones del art. 45 de la Ley $n^{\circ} 2.004$, de 3 de octubre de 1953. Párrafo único. Quedan excluidos de la limitación del art. 177, \$1 1, los contratos de riesgo hechos con la Petróleo Brasileiro S.A., para búsqueda de petróleo, que estén en vigor en la fecha de la promulgación de la Constitución".

8 CONTRERAS (1994) pp. 149-151; VILLAS-BÔAS (1995), pp. 82-83; FIOROTTI (2007) pp. 191-195). 
prácticas de adulteración de combustibles en cinco grandes empresas (BR-Distribuidora, Ipiranga, Shell, Chevron e Esso), que controlan 80\% de la red de estaciones de servicio, 66\% del mercado de gasolina y $76 \%$ del mercado de óleo diesel ${ }^{9}$.

Fernando Henrique Cardoso propuso la "flexibilización" del monopolio de la Unión sobre el petróleo, con el argumento de que habría carencia de recursos para invertir en la explotación petrolifera. La ampliación de las reservas del país sería una tarea que no podría ser mas ejercida solamente por la Petrobras. Además de esto, el discurso en defensa de la propuesta de reforma constitucional enfatizaba en la necesidad de la Petrobras competir con otras empresas y, para eso, la empresa estatal debería perder la responsabilidad de proveer el abastecimiento de petróleo y derivados en el mercado interno. Las funciones de la Petrobras precisarían ser separadas de las funciones de la Unión, que debería retomar el control del sector y establecer la política nacional del petróleo. En suma, la exclusividad de la Petrobras como ejecutora del monopolio estatal sería quebrada ${ }^{10}$.

La propuesta de reforma constitucional obtuvo 364 votos a favor, 141 en contra y 3 abstenciones en la votación del primer turno en la Cámara de Diputados, ocurrida el 7 de junio de 1995. Después de la aprobación de la propuesta de reforma constitucional en la Cámara de Diputados, el Presidente Fernando Henrique Cardoso tuvo que comprometerse públicamente a excluir a la Petrobras del programa de privatizaciones, el que fue, posteriormente, asegurado por el artículo $3^{\circ}$ da Ley no 9.491, de 09 de septiembre de 1997. Después de ese compromiso, el Senado realizó las votaciones, el 18 de octubre y el 8 de noviembre de 1995, registrando 60 votos a favor y 15 en contra de la "flexibilización" del monopolio estatal del petróleo.

La Reforma Constitucional n 9, de 09 de noviembre de 1995, extirpó del texto constitucional a la Petrobras como ejecutora única del monopolio, pero mantuvo el monopolio de la Unión sobre el petróleo, que pude explotarlo directamente o por medio de concesiones a empresas estatales o privadas, inclusive de capital extranjero. El legislador ordinario modificó, así, uno de los principios ideológicos originarios establecidos por la Asamblea Nacional Constituyente, consagrando la victoria, por vía de reforma constitucional, de los derrotados en la elaboración de la Constitución de 1988"11.

9 FIOROTTI (2007) pp. 187-189.

10 LIMA (1995) pp. 10640-10643; MENDEZ (1996) pp. 8-10; VALOIS (2000) pp. 116-121; FIOROTTI (2007) pp. 196-197.

11 Artículo 177 de la Constitución de 1988 (redacción alterada por la Reforma no 9/1995): "Constituyen monopolio de la Unión: I - la búsqueda y extracción de los yacimientos de petróleo y gas natural y otros hidrocarburos fluidos; II - el refinamiento del petróleo nacional o extranjero; III - la importación y exportación de los productos y derivados básicos resultantes de las actividades previstas en los incisos anteriores; IV - el transporte marítimo del petróleo bruto de origen nacional o de derivados básicos de petróleo producidos en el País, como asi el transporte, por medio de conducto, de petróleo bruto, sus derivados y gas natural de cualquier origen; $V$ - la búsqueda, la extracción, el enriquecimiento, y reprocesamiento, la industrialización y el comercio de minerales nucleares y sus derivados. $\$ 1 \%$ la Unión podrá contratar con empresas estatales o privadas la realización de las actividades previstas en los incisos I a IV de este artículo observadas las condiciones establecidas en ley. $\S 2^{\circ}$ La ley a que se refiere el $\S 1^{\circ}$ dispondrá sobre: I - la garantía del fornecimiento de los derivados de petróleo en todo el territorio nacional; ll - las condiciones de contratación; III - la estructura y atribuciones del órgano regulador del monopolio de la Unión; § $3^{\circ}$ la ley dispondrá sobre el transporte y la utilización de materiales radioactivos en el territorio nacional." La Reforma Constitucional n 33, de 11 de diciembre de 2001, acrecentó el $\$ 4^{\circ}$ al artículo 177 de la Constitución: "§ $4^{\circ}$ — La ley que instituya contribución de intervención en el dominio económico relativa a las actividades de importación o comercialización 
Después de la aprobación de la Reforma no 9/199512, el Poder Ejecutivo envió al Congreso Nacional, el 05 de julio de 1996, el Mensaje n 639, que se convirtió en el Proyecto de Ley $n^{\circ}$ 2.142/1996, proponiendo que la Petrobras dejase de ser la única ejecutora del monopolio estatal del petróleo y creando la Agencia Nacional del Petróleo (ANP), que sería la responsable por la gestión del monopolio. El Relator en la Cámara, Diputado Eliseu Resende (PFL-MG), elaboró un Proyecto Substitutivo a partir de la propuesta del Ejecutivo, siendo este Substitutivo votado en régimen de urgencia constitucional en la Cámara de los Diputados y en el Senado y convertido en la Ley n ${ }^{0} 9.478$, de 06 de agosto de $1997^{13}$. A pesar de haberse comprometido a no privatizar la Petrobras, con la aprobación de la Ley no 9.478/1997, el Gobierno de Fernando Henrique Cardoso promovió una "privatización parcial" de la empresa, vendiendo cerca de 180 millones de acciones que estaban bajo control de la Unión. La participación de la Unión cayó de 82\% para alrededor de 51\% del total de acciones con derecho a voto. De este total, apenas 25\% fueron adquiridas en Brasil, por 310 mil optantes del FGTS (Fondo de Garantía por Tiempo de Servicio). El resto de las acciones fue vendido para inversores internacionales. Con esta operación, la Petrobras obtuvo la incorporación de una serie de accionistas minoritarios vinculados al capital extranjero, pagando, según Carlos Lessa, dividendos a accionistas residentes en el exterior en volúmenes mucho más elevados que los salarios o intereses pagados por la empresa. Esta alteración societaria tornó la actuación de la Petrobras, mucho más dirigida a intereses comerciales, no necesariamente estratégicos, de lo que venía siendo hasta entonces ${ }^{14}$.

El abastecimiento nacional de combustibles es un servicio de utilidad pública (artículo $1^{\circ}$, $§ 1^{\circ}$ de la Ley $n^{\circ} 9.847$, de 26 de octubre de 1999) ${ }^{15}$. Sin embrago, la Ley no 9.487/1997

de petróleo y sus derivados, gas natural y sus derivados y alcohol combustible deberá atender a los siguientes requisitos: I - la alícuota de la contribución podrá ser: a) diferenciada por producto o uso; b) reducida y restablecida por ato del Poder Executivo, no aplicándosele lo dispuesto en el art. 150, III, b; II — los recursos recaudados serán destinados: a) al pago de subsidios a precios o transporte de alcohol combustible, gas natural y sus derivados y derivados de petróleo; b) al financiamiento de proyectos ambientales relacionados con la industria del petróleo y del gas; c) al financiamiento de programas de infraestructura de transportes". El artículo 177 sería, aún, modificado una vez más por la Reforma Constitucional $n^{\circ} 49$, de 8 de febrero de 2006, que alteró la redacción del inciso $V$ del caput de este artículo (así como la del artículo 21, XXIII): "V—la búsqueda, la extracción, el enriquecimiento, el reprocesamiento, la industrialización y el comercio de minerales nucleares y sus derivados, con excepción de los radioisótopos cuya producción, comercialización y utilización podrán ser autorizadas bajo el régimen de permiso, conforme las líneas $b$ y c del inciso XXIII del caput del art. 21 de esta Constitución Federal". Sobre esta discusión, véase también, ALBINO DE SOUZA, Washington, Teoria da Constituição Econômica cit., pp. 523-527 e 546-547; CLĖVE, Clèmerson Merlin Et FERREIRA MARTINS, Alessandra, "Principios Constitucionais da Atividade Econômica Petrolifera e Lei no 9.478 de 1997", A \& C - Revista de Direito Administrativo e Constitucional no 18, 2004, pp. 45-46; BERNAL, Federico, Petróleo, Estado y Soberanía cit., pp. 228-229 y FEROLLA, Sergio Xavier \&t METRI, Paulo (2006): Nem Todo Ø Petróleo É Nosso (Rio de Janeiro, Paz e terra) pp. 221-222.

12 Sobre los estudios de las empresas de consultoria, nacionales y extranjeras, que elaboraran las propuestas de "apertura" del sector petrolífero brasileño en 1995, llegando algunas a proponer, inclusive, la privatización de la Petrobras, véase DE MIRANDA FERREIRA, Antônio Luis (2005) "A Desmonopolização do Mercado" in PIRES, Paulo Valois (edit.), Temas de Direito do Petróleo e do Gás Natural II (Rio de Janeiro, Lumen Juris) pp. 32-43.

13 VALOIS (2000) pp. 126-129; DE MIRANDA (2005) pp. 45-48; FIOROTII (2007) pp. 202-204.

14 McPHERSON (2003) pp. 195-196, 198 y 201-202; LESSA (2009) p. 92.

15 BUCHEB (2007) pp. 21-23. 
no garantiza el suplemento de petróleo y derivados para el mercado interno a mediano y largo plazo, sino más bien todo lo contrario. Según Clèmerson Clève e Alessandra Martins, la ley trata al petróleo como si fuese un bien perecedero, enfatizando la necesidad de aprovechamiento rápido de las reservas, dentro de los plazos estipulados por la Agencia Nacional del Petróleo, y no de acuerdo con la demanda del país. El artículo 23 de la Ley no 9.478/1997, por ejemplo, omite cualquier disposición sobre la preservación de las reservas petroliferas y de los derechos de explotación de la Unión como criterios para las concesiones, abriendo la posibilidad de que la Agencia Nacional del Petróleo pueda realizar concesiones indiscriminadas e incentivar la explotación predatoria. Ya la determinación del artículo 60 libera la exportación de petróleo y derivados para el caso en que la producción sea superior a la demanda interna, sin preocuparse por la constitución de reservas para la autosuficiencia nacional o la balanza de pagos. Las directrices para importación y exportación de petróleo y derivados, buscando atender las necesidades de consumo interno y el funcionamiento adecuado del Sistema Nacional de Stock de Combustibles, son materia de competencia expresa del CNPE (artigo 2, V da Ley n 9.478/1997). No obstante, a pesar de esto, el Decreto n 2.926, de 7 de enero de 1999, atribuyó la competencia para decidir sobre la exportación de petróleo y derivados a la Agencia Nacional del Petróleo, violando la legislación. El petróleo y el gas natural deben ser destinados preferentemente al mercado interno, a partir de parámetros nacionales, no vinculados a la volatilidad de las cotizaciones internacionales. El control de la balanza de pagos y de las cuentas externas del pais, inclusive, exige un mayor control de la exportación e importación del petróleo, gas y derivados, lo que debería ser hecho exclusivamente por la Petrobras. El accionar de la Agencia Nacional del Petróleo, por lo tanto, debe ser restringido, con el refuerzo de las competencias, inclusive en términos de planeamiento estratégico, del Ministerio das Minas y Energía, del CNPE, de la Petrobras y de la Electrobras. En este sentido, fue extremamente oportuna la creación de la Secretaria Nacional de Petróleo, Gas Natural y Combustibles Renovables, vinculada al Ministerio de Minas y Energía, por el Decreto nº 5.267, de 09 de noviembre de $2004^{16}$.

Los defensores de la Ley no 9.478/1997 alegan que, a partir de su promulgación, la Petrobras pasó a actuar en régimen de libre competencia con otras empresas petrolíferas, debiendo celebrar los contratos de concesión sin cualquier privilegio, como una empresa cualquiera ${ }^{17}$. Sin embrago, la Ley no 9.478/1997 tiene una serie de dispositivos especialmente elaborados con la finalidad de perjudicar la actuación de la empresa estatal. El artículo 33 de la ley establece el plazo de tres años para que la Petrobras prosiga con los trabajos de explotación y desarrollo en los campos en que haya realizado descubrimientos comerciales o inversiones en la explotación. No obstante, solo podrá proseguir en las actividades de producción en el caso de que compruebe su capacidad de inversión. La comprobación financiera de la capacidad de inversión no es exigida, en esta ley, para ninguna otra empresa que pretenda actuar en el sector petrolifero, solo para la Petrobras. Otra disposición discriminatoria es

16 TAVARES (1999) pp. 152-154; VALOIS (2000) pp. 130-132; CLĖVE \& FERREIRA (2004) pp. 47-50; BERNAL (2005) pp. 233-234; FEROLLA \& METRI (2006) pp. 63-64, 117-118, 196-198 y 213-214.

17 MENDEZ (1996) pp. 11-12; BARROSO (2002) pp. 406-407 y 411. 
la que consta en los artículos 58 y 59, que facultan a cualquier interesado el uso de los ductos de transporte y de los terminales marítimos existentes o a ser construidos. 0 sea, la Petrobras debe compartir toda a su infraestructura, construida con recursos públicos, con sus competidores privados, sin que estos tengan que invertir nada, bastando que "haya comprobado interés de tercero en su utilización" (artículo 59) ${ }^{18}$.

El petróleo y los recursos minerales son bienes de la Unión por determinación de los artículos 20, IX y 176, caput de la Constitución de 1988. El debate se da en torno a su clasificación como bienes públicos de uso especial o bienes públicos dominicales ${ }^{19}$. Para los defensores del petróleo y de los recursos minerales como bienes dominicales, esta definición no impediría la posibilidad de ser afectados para usos específicos. Estos recursos serian bienes públicos consumibles, afectados, pero alienables, pues tendrian una finalidad que implica su utilización, por lo tanto, su alienación.

Estas concepciones, sin embargo, están equivocadas. El petróleo y los recursos minerales son bienes públicos de uso especial, bienes indisponibles cuya destinación pública está definida constitucionalmente: la explotación y el aprovechamiento de sus potenciales. La explotación del petróleo y de los recursos minerales está vinculada a los objetivos finales fundamentales de los artículos 3, 170 e 219 de la Constitución de 1988, o sea, el desarrollo, la reducción de las desigualdades y la garantía de la soberanía económica nacional. Se trata de un patrimonio nacional irrenunciable ${ }^{20}$.

Como consecuencia de esto, la naturaleza juridica del contrato de concesión de explotación de petróleo, asi como el contrato de concesión de extracción de minerales, es la de un contrato de concesión de uso de explotación de bienes públicos indisponibles, cuyo régimen jurídico es distinto en virtud de la Constitución y de la legislación ordinaria, por lo tanto, la de un contrato de derecho público. Estas concesiones son actos administrativos constitutivos en virtud de los cuales el poder concedente (la Unión) delega poderes a los concesionarios para utilizar o explotar un bien público21.

Aun en relación a la naturaleza jurídica del petróleo como bien público, la cuestión de la propiedad sobre el resultado de la extracción del petróleo y gas natural fue debatida en el Supremo Tribunal Federal en el contexto de la Ação Direta de Inconstitucionalidade $n^{\circ}$ 3273-9/DF, presentada por el Gobernador do Paraná, Roberto Requião, alegando la inconstitucionalidad de una serie de dispositivos de la Ley no 9.478/1997, especialmente su artículo 26, caput ${ }^{22}$.

18 TAVARES (1999) p. 153; BERNAL (2005) pp. 228-230.

$19 \mathrm{~N}$. de la T.: En el texto original bens dominicais. Terminología que en el derecho brasileño se utiliza para denominar a los bienes públicos que pertenecen al Estado en su calidad de propietario, sin una destinación publica definida. Pueden ser utilizados para finalidades económicas como la obtención de renta o hasta pueden ser alienados siempre que obedecidas las determinaciones legales.

20 MORAES (2001) pp. 162-163; CLĖVE \& FERREIRA (2004) pp. 43-45; RUY (2005) pp. 11-12; BUCHEB (2007) pp. 5-7.

21 ZANELLA (2010) pp. 39-41y 108-109; DE MORAES (2001) pp. 167-170; RUY (2005) pp. 26-27; BUCHEB (2007) pp. 50-55.

22 Artículo 26, caput de la Ley no 9.478/1997: "La concesión implica, para el concesionario, la obligación de explotar, por su cuenta y riesgo y, en caso de éxito, producir petróleo o gas natural en determinado bloque, confiriéndole la 
Para los defensores de la constitucionalidad del artículo 26, caput de la Ley $n^{\circ}$ 9.478/1997, la Reforma Constitucional no 9/1995 habría equiparado el régimen jurídico aplicable al petróleo y gas al de los demás bienes minerales previstos en el artículo 176 de la Constitución. El concesionario tendría el derecho de propiedad sobre el producto de la extracción, al aplicarse lo dispuesto en el artículo 176, caput de la Constitución al petróleo, regido por el artículo 177, con la interpretación de que el artículo 176 sería la "regla general" para la explotación de todos los recursos minerales de titularidad de la Unión, inclusive el petróleo ${ }^{23}$.

Los que sostienen la inconstitucionalidad de la Ley no 9.478/1997 afirman que los yacimientos de petróleo son bienes públicos indisponibles de la Unión. Sin embargo, el artículo 26 de la Ley no 9.478/1997 atribuye la propiedad del petróleo, cuando extraído, al concesionario. La Ley no 9.478/1997 habría migrado, así, del monopolio estatal al extremo opuesto de la titularidad de los concesionarios. Este artículo sería inconstitucional, pues la propiedad del petróleo y gas natural, aún después de extraídos, de acuerdo con el artículo 20, IX de la Constitución, es de la Unión. La cuestión de la inconstitucionalidad del artículo 26 de la Ley no 9.478/1997 estaría ligada también a la manutención o no del monopolio estatal del petróleo. Si el monopolio fue mantenido por la Reforma Constitucional no 9/1995, la Unión no podría transferir la propiedad del producto de la extracción para el concesionario ${ }^{24}$.

La mayoría del Supremo Tribunal Federal apoyo el voto elaborado, después de un nuevo pedido de vista, por el Ministro Eros Grau, en la sesión ocurrida el 16 de marzo de 2005, considerando improcedente la acción directa de inconstitucionalidad. En su voto, el Ministro Eros Grau discordó de la naturaleza jurídica del petróleo como bien público de uso especial, entendiéndolo como un bien público dominical. A pesar de haber afirmado, correctamente, que el monopolio dice respecto a la actividad económica, y no a la propiedad de los bienes, el Ministro Eros Grau defendió la posición de que la transferencia de la propiedad del resultado de la extracción de los yacimientos de petróleo y gas natural para terceros seria constitucional, pues no afectaría el monopolio estatal de la actividad, previsto en el artículo 177. De este modo, sería aplicable al petróleo y al gas natural el mismo trato dado a los concesionarios de la explotación de los demás recursos minerales, conforme dispuesto en el artículo 176, caput de la Constitución. Además de esto, la propiedad del concesionario sobre el producto de la extracción sería relativa, pues su comercialización continuaría siendo administrada por la Unión, por medio de la Agencia Nacional del Petróleo.

La decisión de la mayoría de los Ministros del Supremo Tribunal Federal fue, lamentablemente, totalmente equivocada. El artículo 26, caput de la Ley no 9.478/1997 es inconstitucional, pues viola los artículos 20, IX y 177 de la Constitución. El petróleo y el gas natural son bienes inalienables de la Unión, bienes de uso especial, como los demás

propiedad de esos bienes, después de extraidos, con los cargos relativos al pago de los tributos incidentes y de las participaciones legales o contractuales correspondientes" (el destacado me pertenece).

23 SANTOS (2005) pp. 423-427; BUCHEB (2007) pp. 9-11.

24 TAVARES (1999) p. 153; VALOIS (2000) pp. 129-130; CLĖVE \& FERREIRA (2004) p. 49; FEROLLA \& METRI (2006) pp. 261-163 e 266; BUCHEB (2007) pp. 11-15 e 28-29. 
recursos minerales. La diferencia entre el régimen jurídico de los recursos minerales en general (artículo 176) y el régimen jurídico del petróleo, gas y minerales nucleares (artículo 177) es, justamente, el hecho de estos últimos haber sido monopolizados por la Unión. La autorización constitucionalmente manifestada en el artículo 176, caput de que el producto de la extracción mineral es propiedad del concesionario es una excepción de alienabilidad al régimen jurídico de los bienes minerales, por eso es expresa constitucionalmente. La regla es la inalienabilidad de los recursos minerales. En los casos de concesión, es estipulada la excepción del artículo 176, caput. Si, de hecho, como entendió la mayoría del Supremo Tribunal Federal, la Reforma no 9/1995 y la Ley no 9.478/1997 tornaron aplicable a la explotación del petróleo y del gas natural las mismas reglas generales previstas en el artículo 176, especialmente la atribución de la propiedad del producto de la extracción al concesionario, no resta entonces ninguna distinción entre una concesión de explotación de minerales y una concesión de explotación de petróleo o gas natural. Ahora bien, la propiedad de la Unión sobre el producto de la extracción del petróleo y gas natural es mantenida por la Constitución justamente por el hecho de esta actividad ser monopolizada, a diferencia de la extracción de minerales en general. Con la atribución de la propiedad del producto de la extracción del petróleo y gas natural al concesionario, el control de la actividad petrolífera deja, concretamente, de ser monopolio de la Unión, lo cual viola los artículos 20, IX e 177 de la Constitución de 1988.

En prácticamente todos los paises del mundo, el petróleo, el gas natural y los demás recursos minerales pertenecen al Estado. Las principales excepciones son los Estados Unidos y Canadá25. Los sistemas de contratos de explotación de petróleo más utilizados son: contrato de concesión, contrato de producción compartida ${ }^{26}$ y contrato de servicios ${ }^{27}$.

El contrato de concesión (concessionary system ou royalty/tax system - r/t system) no implica la propiedad estatal sobre el producto de la extracción, permitiendo la propiedad privada de los recursos minerales. El concesionario (sea una empresa o un consorcio) adquiere el derecho exclusivo de explotar en aquella área determinada, por su cuenta y riesgo, tornándose propietario del petróleo producido, lo cual es, en Brasil, inconstitucional, conforme los artículos 20, IX y 177 de la Constitución de 1988. El ingreso estatal generalmente proviene de los royalties, impuestos y bonus. De acuerdo con el análisis de Juan Pablo Pérez Alfonso, criticando el modelo venezolano de concesiones, la diferencia jurídica básica de los tipos de contrato se manifiesta en la diferencia entre derechos reales y derechos contractuales. El titular de la concesión tiene derechos reales sobre el petróleo a ser explotado ${ }^{28}$. El contrato de concesión es el más tradicional y es muy cuestionado, pues no permite la apropiación estatal de parte considerable de la renta petrolifera generada. En Venezuela, por ejemplo, desde 1946, la decisión de los gobiernos democráticos fue la de no permitir ninguna concesión más ("principio de no más concesiones"), teniendo en vista

25 JOHNSTON (2007) p. 68.

26 N. de la T.: En el texto original, "contrato de partilha de produção".

27 JOHNSTON (2007) pp. 65-67.

28 PEREZ (1967) pp. 39-40; KLAPP (1987) p. 72; JOHNSTON (1994) p. 21; MACHMUD (2000) pp. 34-37; JOHNSTON (2003) pp. 18-27; JOHNSTON (2007) pp. 56-60; FIOROTTI (2007) pp. 71-72, 75-77 y 205. 
la falta de inversiones y de desarrollo generados por el antiguo sistema de concesiones, finalmente abolido con la nacionalización de la industria petrolífera en aquel país, en $1975^{29}$.

Del mismo modo, los países productores de petróleo del Mar del Norte, destacándose Reino Unido y Noruega, decidieron no aceptar, ya en la década de 1960, el padrón tradicional de explotación por medio del sistema de concesiones, imponiendo una mayor participación y dirección de la industria petrolifera por parte de sus Estados. Las alteraciones instituidas por los dos paises, ambos regimenes democráticos consolidados, ampliaron el papel del Estado en la explotación petrolifera y en la apropiación de las rentas generadas por el sector. Al enfrentar los intereses de las multinacionales petroleras y las prescripciones de política económica neoclásica, el Reino Unido y Noruega priorizaron su propia política económica nacional, y no los intereses de los grupos económicos privados. El llamado "North Sea model" concedia áreas menores que el modelo de concesión tradicional. Aunque las empresas privadas pudiesen actuar directamente en la explotación y producción, fueron implementadas una serie de tasaciones suplementares e imposiciones legales para retener buena parte de la renta generada por el petróleo, como la llamada "participación gubernamental", se amplió el control estatal sobre los recursos producidos, por medio del papel central de las empresas estatales (British National Oil Company - BNOC, privatizada por Margaret Thatcher en la década de 1980, y la Statoil, aún hoy bajo el control del Estado noruego), buscando acomodar los intereses privados bajo el control directo estatal. El modelo implementado transformó, así, al Estado en el principal operador de la industria petrolifera y el líder en la acumulación de capital, reforzando la supremacía del Poder Público en relación al capital privado en las economías británica y noruega ${ }^{30}$.

En Brasil, por la legislación adoptada en 1997, el contrato de concesión tiene como partes contratantes a la Agencia Nacional del Petróleo (poder concedente) y la empresa (concesionaria), que tendrá la propiedad del petróleo y gas efectivamente producidos en virtud de un dispositivo flagrantemente inconstitucional (el artículo 26 de la Ley no 9.478/1997). El período de la concesión es de 27 años para la producción, después de la declaración de comercialidad del descubrimiento que debe ser hecha por el concesionario.. ${ }^{31}$.

Además de los contratos de concesión, existen también los contratos de producción compartida (production-sharing contracts), que garantizan la propiedad estatal sobre los productos petroliferos antes de ser comercializados. Son los contratos más utilizados por los Estados productores de petróleo. El primer contrato de este tipo fue firmado en Indonesia, en 1966. Los riesgos por la inversión y el desarrollo de la producción son de las empresas contratadas. Después del inicio de la producción, las empresas pueden recuperar sus gastos y costos de operación de una porción denominada "cost oil". La parte remaneciente, el "profit oil", es dividida entre la empresa y el gobierno, en la proporción establecida en el contrato. El Estado mantiene total dominio sobre la propiedad de los recursos minerales, sobre los

29 PEREZ (1967) pp. 47-58 e 87-88; MUGHRABY, (1966) pp. 45-54.

30 NORENG (1980) pp. 14-15, 29-35, 120-127, 144-151, 181-182, 211-212, 214-216 y 261-262.

31 FIOROTTI (2007) pp. 289-291. 
equipos e instalaciones y sobre el gerenciamiento de las operaciones de producción de petróleo. En palabras de Juan Pablo Pérez Alfonso, los derechos reales sobre el petróleo no salen nunca del dominio del Estado ${ }^{32}$.

Los contratos de servicio (service agreements), por su parte, son instituidos para la ejecución de servicios mediante pago, manteniendo al Estado como propietario de todos los activos petroliferos. En caso de no poseer la cláusula de riesgo, los riesgos son del Estado contratante. En caso de poseer la cláusula de riesgo, los riesgos y costos son de la empresa contratada ${ }^{33}$. Los defensores de los contratos de riesgo en los años 1970 afirmaban que este tipo de contrato no afectaba al monopolio estatal, pues había substituido, en los países que lo adoptaron, a los "antiguos regímenes de concesión", en los cuales la propiedad del petróleo era transferida a los concesionarios, dejando en sus manos la decisión sobre aumentar o disminuir la producción, de acuerdo con sus intereses privados. La mayor parte de los conflictos sobre el petróleo, inclusive, habria sido generada por el modelo de explotación de yacimientos, con base en los contratos de concesión ${ }^{34}$.

El modelo de los contratos de concesión, criticado inclusive por el régimen militar, fue adoptado por Brasil en 1997, modelo éste que no podría ser más inadecuado, teniendo en vista el interés público en la explotación y producción de petróleo y gas natural. Además de sus problemas estructurales, mencionados anteriormente, no se puede dejar de mencionarse el hecho de que la Ley no 9.478/1997, que instituyó el modelo de las concesiones petroliferas, es inconstitucional, pues el concesionario no puede ser propietario del producto de la extracción, bajo pena de contrariar el hecho de que el petróleo es un bien público de uso especial y es también monopolizado por el Estado (artículos 20, IX y 177 de la Constitución de 1988). También hay necesidad de revisión de la Ley no 9.478/1997 para rescatar el papel de la Petrobras como ejecutora de la política nacional del petróleo ${ }^{35}$.

El debate sobre la apropiación del excedente de las actividades de explotación de petróleo y recursos minerales ganó un nuevo aliento con el descubrimiento de los yacimientos del pre-sal. Las reservas de petróleo y gas natural situadas en la camada del pre-sal, o sea, abajo de la camada de sal del subsuelo de la plataforma continental, fueron anunciadas en 2006. Los descubrimientos iniciales se refieren a los yacimientos situados a $300 \mathrm{~km}$ de la costa aproximadamente, entre Espírito Santo y Santa Catarina. Las reservas están localizadas cerca de 2 mil quilómetros abajo del nivel del agua y de una camada de 5 mil metros de

32 PEREZ (1967) pp. 39-40; KLAPP (1987) pp. 73-74; JOHNSTON (1994) pp. 21-23 y 39-40; MACHMUD (2000) pp. 37-39; JOHNSTON (2003) pp. 28-39; JOHNSTON (2007) pp. 56-58 y 60-62; FIOROTTI (2007) pp. 72-73, 78-79 y 301-304.

33 JOHNSTON (1994) pp. 23-24 y 87-88; MACHMUD (2000) p. 39; JOHNSTON (2003) pp. 41-44; JOHNSTON (2007) pp. 62-64; FIOROTI (2007) p. 78. Hay, inclusive, contratos de participación y asociación que permiten asociaciones entre la empresa petrolifera estatal y otras empresas petroliferas, generalmente en contratos de concesión. Un ejemplo es la joint-venture entre la empresa estatal y empresas privadas, nacionales o internacionales. La mayor parte de los contratos modernos posee una cláusula de participación accionaria del Estado o de su empresa estatal petrolifera. JOHNSTON (1994) pp. 102-107; JOHNSTON (2003) pp. 52-53; FIOROTTI (2007) pp. 79-80. 
rocas y sal. Las investigaciones geológicas pueden ampliar estos descubrimientos, además de confirmar si serían varios yacimientos o un único bloque. Las estimaciones hablan de un potencial de más de 70 billones de barriles de petróleo, de buena calidad (en principio se trata de óleo leve), lo que transformaría a Brasil en uno de los principales productores del mundo. Para esto, son necesarias voluminosas inversiones, que serian compensadas por la productividad de los pozos (estimada en 20 mil barriles/día), a depender de los precios del petróleo en el mercado internacional ${ }^{36}$.

La primera y más urgente medida tomada por el Presidente Luís Inácio Lula da Silva fue proponer un cambio en el modelo de contrato de explotación de petróleo que estaba entonces vigente en Brasil, por medio del Proyecto de Ley no 5.938/2009. Además de este proyecto, fueron presentados otros tres proyectos de ley al Congreso Nacional buscando alterar la legislación petrolifera del país y propiciar mejores condiciones para el aprovechamiento de los yacimientos del pre-sal: Los Proyectos de Ley n 5.939/2009, que autorizaba la creación de una empresa pública, gestora de los nuevos contratos de producción compartida; $n^{\circ}$ 5.940/2009, que estipulaba la creación del Fondo Social, formado a partir de los recursos obtenidos con la explotación de los yacimientos del pre-sal y n 5.941/2009, que proponía la autorización para la Unión ceder onerosamente a la Petrobras, sin licitación, el ejercicio de la búsqueda y extracción de petróleo y gas natural en las áreas no concedidas del pre-sal. Después de una serie de debates intensos en todo el pais y en el Congreso Nacional, los proyectos fueron convertidos en ley, en el transcurso del año 2010.

El primero de los proyectos que fue aprobado, Proyecto de Ley $n^{\circ} 5.941 / 2009$, se transformó en la Ley no 12.276, de 30 de junio de 2010, que autoriza a la Unión a ceder onerosamente a la Petrobras el ejercicio de las actividades de búsqueda y extracción de petróleo y gas en las áreas no concedidas del pre-sal. La cesión produce efectos hasta la extracción del valor equivalente a 5 billones de barriles de petróleo (artículo 1ㅜ, \$2 ${ }^{\circ}$ de la Ley no 12.276/2010), autorizando a la Unión a ampliar, así, su participación en el capital de la Petrobras (artículo $9^{\circ}$ de la Ley no 12.276/2010). El valor del barril de petróleo para la cesión onerosa fue fijado en 8,51 dólares por el Presidente Lula, después del análisis de los estudios técnicos realizados a pedido de la Agencia Nacional del Petróleo. Con la cesión onerosa de la Unión, se promovió una operación de capitalización de la Petrobras, finalizada el 24 de septiembre de 2010, que recaudó cerca de 120 billones de reales, de los cuales 74,8 billones fueron provenientes de la Unión. ${ }^{37}$. Los recursos obtenidos garantizan el cumplimiento del plan de inversión de la empresa para la explotación de petróleo en los yacimientos del pre-sal

36 LESSA (2009) pp. 93-95.

37 Otro instrumento legal esencial para la capitalización de la Petrobras fue la edición de la Medida Provisoria n 500, de 30 de agosto de 2010, hoy convertida en la Ley no 12.380, de 10 de enero de 2011, que autoriza a la Unión, las entidades de la administración pública federal y los fondos del cual el Tesoro sea el único accionista, como el Fondo Soberano del Brasil, a adquirir, permutar y ceder acciones entre sí. La Ley no 12.380/2011 permite que la Unión adquiera acciones excedentes para mantener el control accionario en sociedades de economía mixta federales (artículo 10), lo que viabilizó, entre otras medidas, el proceso de capitalización de la Petrobras. Aún sobre el formato de medida provisoria, esta autorización legal (artículo 10, III de la Medida Provisoria n500/2010) permitió al Fondo Soberano del Brasil y al BNDES adquirir bloques de acciones de la Petrobras cuya preferencia de compra era de la Unión, durante la operación de capitalización de la empresa. 
hasta 2014. Además de eso, la participación de la Unión pasó de ser de 40\% del capital y 55\% de las acciones ordinarias para cerca de $47 \%$ del capital y $64 \%$ de las acciones ordinarias de la Petrobras, lo que aún está muy lejos de los $82 \%$ de acciones ordinarias que la Unión detentaba antes de la "privatización blanca" del gobierno de Fernando Henrique Cardoso.

Aún en relación a este punto, creo que algunas consideraciones deben ser hechas. La sociedad de economía mixta tiene como caracteristicas esenciales la no exclusividad del capital público, la necesidad de ser su creación autorizada por ley y la forma de sociedad anónima. La sociedad de economía mixta es un instrumento de actuación del Estado, no existe para atender intereses privados. Como afirma Celso Antônio Bandeira de Mello, la personalidad jurídica de derecho privado de la sociedad de economía mixta es un mero expediente técnico, pues ella maneja recursos mayoritariamente públicos ${ }^{38}$. No hay, por lo tanto, igualdad entre los accionistas minoritarios y el Estado controlador de la sociedad. El Estado posee una serie de prerrogativas y poderes exorbitantes en la gestión de las sociedades de economía mixta. El Estado se relaciona con la estructura societaria de la sociedad de economía mixta no apenas como un accionista, mas como "Estado-poder". Si el Estado actúa en igualdad con los demás accionistas, la empresa no es una sociedad de economía mixta, sino una mera sociedad con participación estatal. La misión de la Petrobras no es "defender sus accionistas". Y, aún si fuese eso verdad, no se puede olvidar que el propietario del control accionario de la Petrobras, asi como de cualquier empresa estatal, es el pueblo brasilero.

La Ley n 12.304, de 2 de agosto de 2010, autoriza al Poder Ejecutivo a crear la empresa pública Empresa Brasileira de Administración de Petróleo y Gas Natural S.A. - PreSal Petróleo S.A. (PPSA) ${ }^{39}$, vinculada al Ministerio de Minas y Energía. La PPSA está siendo creada para gestionar los contratos de producción compartida celebrados y los contratos de comercialización de petróleo y gas natural de la Unión (artículo $2^{\circ}$ de la Ley n 12.304/2010). Sus funciones no son de ejecución, sino de gestión contractual, fiscalización y representación de la Unión en relación a todos los contratos de producción compartida celebrados por el Ministerio de Minas y Energía (artículos $2^{\circ}$ y $4^{\circ}$ de la Ley $n^{\circ} 12.304 / 2010$ ). Como empresa pública, todo su capital social pertenece a la Unión (artículo 6º de la Ley no 12.304/2010).

El Proyecto de Ley n 5.938/2009, enviado por el Presidente Lula al Congreso Nacional, tuvo como eje central el cambio de régimen de explotación de los yacimientos del pre-sal y áreas estratégicas. El texto de este proyecto fue votado en conjunto con el del Proyecto de Ley $n^{\circ} 5.940 / 2009$, que proponía la creación del Fondo Social, siendo ambos proyectos de ley consolidados en un texto único y aprobados como la Ley no 12.351, de 22 de diciembre de 2010. Con la nueva ley, el régimen de explotación y producción de petróleo y gas natural de los yacimientos del pre-sal y en las áreas consideradas estratégicas por el Poder ejecutivo pasan del inadecuado e inconstitucional contrato de concesión para el contrato de producción compartida (artículo $3^{\circ}$ de la Ley no 12.351/2010). El modelo de producción compartida es mucho más apropiado para la explotación de petróleo por concesionarios o contratados,

38 BANDEIRA DE MELLO (2006) pp. 178-183.

39 La sigla propuesta originariamente para la PPSA, PETRO-SAL, fue abandonada en razón de que ya existía una empresa con esta denominación. 
cuya propuesta sea considerada más ventajosa de acuerdo con el criterio de la oferta de mayor excedente en óleo para la Unión, o sea, de la parcela de producción a ser repartida entre la Unión y el contratado, cuyo porcentaje mínimo es propuesto por el Ministerio de Minas y Energía al Consejo Nacional de Política Energética (artículos 20, III, 10, III, 'b' y 18 de la Ley $\left.n^{\circ} 12.351 / 2010\right)$. La propiedad del petróleo y del gas natural no es atribuida, de forma inconstitucional, al contratado. El petróleo y el gas natural continúan bajo el dominio de la Unión, como determinan los artículos 20, IX y 177 de la Constitución. El contratado asume todos los riesgos (artículos 20, I, 50, $6^{\circ}$ y 29 , II y $X$ de la Ley $n^{\circ} 12.351 / 2010$ ) y es remunerado por sus actividades (el "costo en óleo" del artículo $2^{\circ}$, II de la Ley n 12.351/2010). El plazo de vigencia del contrato es limitado a 35 años (artículo 29, XIX de la Ley no 12.351/2010)

El Ministerio de Minas y Energía readquiere el control sobre el planeamiento del sector de petróleo y gas natural (artículo 10, I de la Ley no 12.351/2010) y pasa a celebrar los contratos en nombre de la Unión, cuya gestión cabe a la PPSA (artículo $8^{\circ}$ de la Ley no 12.351/2010). La PPSA es, también, integrante obligatoria de todos los consorcios de explotación, sea con la Petrobras separadamente, sea en conjunto con la Petrobras y otros licitantes (artículos 19, 20, caput y 21 de la Ley no 12.351/2010) y debe designar la mitad de los integrantes del comité operacional (artículo 23, párrafo único de la Ley no 12.351/2010), responsable por la administración del consorcio (artículos 22 y 24 de la Ley no 12.351/2010), inclusive su presidente, que tiene poder de veto y voto de calidad (artículo 25 de la Ley n ${ }^{\circ}$ 12.351/2010).

La Petrobras será la operadora de todos los bloques contratados bajo el régimen de producción compartida, con participación mínima asegurada de 30\% en los consorcios de explotación, pudiendo ser esta participación mínima ampliada a partir de propuesta del Ministerio de Minas y Energía al Consejo Nacional de Política Energética (artículos 40, 10, III, 'c', 19, 20 y 30 de la Ley no 12.351/2010). La Unión, también puede contratar a la empresa estatal directamente, sin licitación, para realizar estudios exploratorios (artículo 70, párrafo único de la Ley no 12.351/2010) o para explotar y producir en casos que sea necesario preservar el interés nacional o la prosecución de los objetivos de la política energética (artículos 8०, I y 12 de la Ley no 12.351/2010). La comercialización del petróleo, gas natural y otros hidrocarburos destinados a la Unión será realizada por las normas de derecho privado, sin licitación, de acuerdo con las directrices definidas por el Consejo Nacional de Política Energética (artículos 90, VI y VII y 45, caput de la Ley no 12.351/2010). La PPSA es la representante de la Unión para la comercialización de estos bienes y puede contratar directamente a la Petrobras, dispensada la licitación, como agente comercializador del petróleo, gas natural e hidrocarburos de la Unión (artículo 45, párrafo único de la Ley no 12.351/2010). La previsión de la Petrobras como operadora única no es ninguna innovación brasilera en la legislación petrolifera. Este tipo de previsión existe en varios regímenes de explotación petrolifera, en la mayor parte de las regiones productoras del mundo ${ }^{40}$.

El mismo argumento utilizado durante la "Campaña del Petróleo", en la década de 
1950, fue accionado nuevamente contra la presencia del Estado en el sector petrolífero ${ }^{41}$. Los críticos de la propuesta encaminada de cambio del modelo de explotación alegaron que la Reforma Constitucional no 9, de 1995, habría instaurado el régimen de libre competencia en el sector petrolifero. Para estos autores, la ideología adoptada por la Constitución de 1988 para el petróleo tendría como objetivo la adopción de la "regulación para la competencia", esto es, la regulación de la actividad monopolizada debería ser efectuada de modo de introducir la competencia en el sector. 0 sea, la apertura del sector petrolífero sería una "exigencia constitucional"42. Lógicamente, esta "regulación para la competencia", que sería justificada por la globalización y por los "beneficios traídos a la sociedad" (cualquiera que sean estos), debería, como todos los sectores relegados a la iniciativa privada en Brasil, proporcionar incentivos fiscales y financiamiento público para los agentes económicos privados ${ }^{43}$. Lo curioso es exigir competencia en un sector que es monopolizado constitucionalmente por el Estado.

La Reforma Constitucional no 9/1995 dio a la Unión la opción de elegir entre el mantenimiento del sistema de actuación estatal directa o la adopción de otro sistema, con la posibilidad de contratación de empresas estatales y privadas. La Unión, por lo tanto, puede actuar directamente en el sector de petróleo, por medio de empresa estatal bajo su control accionario (artículo 62 de la Ley no 9.478/1997, que garantiza el control accionario de la Unión sobre la Petrobras). El monopolio estatal en el ejercicio de las actividades en el sector petrolífero fue extinto, pero no el monopolio estatal de estas actividades. El régimen jurídico-constitucional del petróleo es un caso típico de ejercicio del monopolio estatal con "quiebra de reserva" ("Verwaltungsmonopol mit Durchbrechungsvorbehalt"), por medio de concesiones a particulares. La Unión es quien tiene la competencia constitucional de decidir quién puede ejercer las actividades económicas en el sector de petróleo y gas natural, o sea, de acuerdo con Alexandre de Moraes, hay un "monopolio de elección del Poder Público"44.

El trato diferenciado concedido a la Petrobras no vulnera el artículo173, §1이 II de la Constitución, que determina que las sociedades de economía mixta que explotan actividad económica en sentido estricto deben sujetarse al régimen jurídico propio de las empresas privadas. Este artículo es, según Celso Antônio Bandeira de Mello, interpretado de forma exagerada, pues la propia Constitución diferencia los regímenes jurídicos de las empresas privadas y de las empresas estatales en varios pasajes, no estableciendo el mismo régimen de las empresas privadas para las estatales en todas las situaciones ${ }^{45}$.

Uno de los problemas creados con la aprobación de la Ley nº 12.351/2010 es el de la existencia de un modelo dual de explotación del petróleo y del gas natural en el país, con áreas sometidas al régimen jurídico del contrato de producción compartida (Ley

41 LESSA, Carlos (2004) pp. 22-25.

42 BARROSO (2002) p. 411; MARTINS (2006) pp. 62-63, 65-73, 157-169 y 171-235).

43 COUTO (2006) pp. 114-122, 136 y 220-225.

44 BADURA (1963) pp. 258-259; DE MORAES (2001) pp. 163-164 y 166-167; RUY (2005) pp. 22-27; BUCHEB (2007) pp. 123-124.

45 BANDEIRA DE MELLO (2006) pp. 183, 185-188 y 191-192. 
$n^{\circ} 12.351 / 2010$ ) y áreas sometidas al régimen jurídico del contrato de concesión (Ley $n^{\circ}$ 9.478/1997). Esta superposición de regímenes jurídicos, uno de ellos, el de la concesión, inclusive, inconstitucional, no trae ningún beneficio al país. La mejor alternativa seria la unificación del modelo de explotación de los recursos petroliferos, de preferencia bajo un régimen adecuado al texto constitucional, como el modelo de la producción compartida, que mantiene el dominio de la Unión sobre bienes públicos de uso especial, conforme determinan los artículos 20, IX y 177 de la Constitución de 1988. La ampliación del control estatal, socialización, reestatización o renacionalización del petróleo y gas natural, cualquiera sea la denominación de este proceso, es esencial para que pueda ocurrir su reapropiación popular, transformando bienes comerciales en bienes sociales. El petróleo y los recursos minerales constituyen los elementos clave para promover el desarrollo autónomo del pais, por lo tanto, redireccionar los recursos minerales para el desarrollo del mercado interno y para la industrialización significa también concretar nuestra soberanía económica ${ }^{46}$.

En la descripción de Adriana Fiorotti Campos, los principales instrumentos fiscales utilizados por los paises productores de petróleo para recaudar la mayor renta petrolífera posible son: el bonus de asignatura (pagado en el momento de la asignatura del contrato o de la otorga de la concesión) y el bonus de producción (pagado en el momento del descubrimiento y durante el período de producción); el pago por la retención del área, o tasa de ocupación (pagada anualmente para mantener al Estado en la administración de las actividades petroliferas); el royalty (proveniente del privilegio de utilización de un recurso no renovable); el impuesto a la ganancia; la división de lucros extraordinarios (cuando hay producción en campos con lucros extraordinarios o aumento de los precios del petróleo) y la participación gubernamental (pago progresivo en los casos de elevado volumen de producción $)^{47}$.

El debate sobre los royalties provenientes de la explotación de petróleo y gas natural es marcado por los argumentos de cuño regionalista. Para garantizar la aprobación de la Ley n 9.478/1997 en el Congreso Nacional, el Gobierno Fernando Henrique Cardoso concordó con el aumento de la participación de los Estados y Municipios en los royalties del petróleo y gas natural, inclusive y especialmente de la plataforma continental. De la misma forma, la discusión más intensa de la propuesta de alteración de la legislación del régimen de explotación de los yacimientos del pre-sal giró en torno a la distribución de los royalties. Al sancionar la Ley no 12.351/2010, el Presidente Lula vetó todo el texto del artículo 64 y sus párrafos, y envió un nuevo proyecto de ley, el Proyecto de Ley n 8.051/2010, al Congreso Nacional buscando tratar nuevamente la cuestión. Este proyecto, después de intensos debates en el Congreso Nacional, resultó en la Ley no 12.734, de 30 de noviembre de 2012, que amplió la participación en la distribución de los royalties del petróleo para todos los Estados y Municipios del país. Esta tuvo buena parte de su texto vetado por la Presidente Dilma Roussef, pero el veto presidencial fue rechazado por el Congreso Nacional a inicios

46 DE MATTOS \& QUAGLINO (1993) p. 200; BERNAL (2005) pp. 24-25, 30-31, 192-193 y 206-209; LESSA (2009) pp. 92 y $98-100$.

47 FIOROTI (2007) pp. 66-68. 
de 2013. Acto seguido al rechazo del veto, los Gobernadores del Estado de Espírito Santo y del Estado de Rio de Janeiro, la Asamblea Legislativa del Estado do Rio de Janeiro y el Gobernador del Estado de São Paulo entablaron, el 15 de marzo de 2013, acciones directas de inconstitucionalidad (ADI no 4.916, 4.917, 4.918 e 4.920) frente al Supremo Tribunal Federal, solicitando la repartición más igualitaria de los royalties entre todos los miembros de la Federación. La Ministra Cármen Lúcia Rocha declaró procedente, el 18 de marzo de 2013, el pedido de tutela anticipada, suspendiendo los efectos de la Ley no 12.734/2012, y no hay, hasta el momento, ninguna decisión del Supremo Tribunal Federal sobre la distribución de los royalties del petróleo.

Independientemente de la posición que será tomada por el Supremo Tribunal Federal, debo destacar que toda la justificación y la defensa del pago de royalties a los Estados y Municipios es realizada en base a disputas federativas y argumentos regionalistas. El criterio de distribución de los valores del pago de los royalties del petróleo es exclusivamente territorial, fundado en la proximidad física con el lugar de la explotación. Las reglas establecidas dan derecho a la recepción de royalties a los Estados y Municipios confrontantes, o sea, la distancia física es lo más relevante, no la efectiva presencia de capitales vinculados al sector petrolifero. Además de esto, no hay techo para las transferencias y el prorrateo es determinado por categorias de producción, dividiéndose los Municipios en zona de producción primaria, zona de producción secundaria y zona limitrofe. Los criterios legales llevan en consideración también la presencia de instalaciones de embarque y desembarque y de instalaciones industriales para el procesamiento, tratamiento, almacenamiento y escurrimiento del petróleo y gas, pero no son criterios establecidos para medir el impacto proporcional a la populación de las áreas involucradas. No hay, así, ninguna evaluación sobre el efectivo impacto económico y social de las actividades petroliferas sobre el territorio, mucho menos una preocupación con el futuro económico de la región de explotación petrolifera después del agotamiento de los yacimientos ${ }^{48}$.

El resultado de la lógica regionalista que impera en la repartición de los royalties del petróleo es la concentración espacial de estos recursos, principalmente en el Estado de Rio de Janeiro. De acuerdo con los datos aportados por Rodrigo Serra, el porcentaje de distribución regional de los royalties del petróleo entre las diversas regiones brasileiras, en el año de 2005, fue de 3,2\% para la Región Norte, 11,4\% para la Región Nordeste, 84,4\% para la Región Sudeste, 1\% para la Región Sur y 0\% para la Región Centro-Oeste. Solamente el Estado do Rio de Janeiro recibió $46,7 \%$ del total de recursos recaudados como royalties del petróleo. Bruno de Oliveira Cruz y Márcio Bruno Ribeiro también comprueban la concentración espacial de los recursos petroliferos y agregan un dato, a partir de la clasificación adoptada por la Política Nacional de Desarrollo Regional (PNDR) del Ministerio de la Integración Nacional: los Municipios situados en regiones consideradas de alta renta habrian recibido 57,3\% del total de los royalties distribuidos en 2007. Los Municipios situados en regiones consideradas dinámicas recibieron 26,8\% y los Municipios situados en regiones consideradas de baja renta 
o estancadas, o sea, consideradas como prioritarios para la Política Nacional de Desarrollo Regional, recibieron apenas 15,9\% del total de royalties en $2007^{49}$.

Los royalties pagados a los Estados, Distrito Federal y Municipios como resultado de la explotación de petróleo y gas natural o la compensación financiera por esa explotación pueden ser, aún, cuestionados en virtud de esta explotación ocurrir, mayoritariamente, en la plataforma continental brasileña. La Convención de las Naciones Unidas sobre el Derecho del Mar, de 1982, garantiza el derecho de los Estados costeros sobre la plataforma continental contigua a sus territorios. El límite de 200 millas puede ser ampliado para 350 millas, cumpliéndose determinadas condiciones que demuestren la efectiva explotación de los recursos de la plataforma continental. La Convención también aseguró el derecho de los Estados costeros a la zona económica exclusiva de 200 millas, buscando atenuar la proclamación de varios Estados, como Brasil, de soberanía sobre el mar territorial de 200 millas a partir de la costa. Los derechos de la zona económica exclusiva y de la plataforma continental aseguran la explotación económica, y el manejo y la conservación de los recursos naturales, sea en el agua, suelo o subsuelo marítimo. De acuerdo con Vicente Marotta Rangel, la plataforma continental y la zona económica exclusiva no se excluyen, pues son complementares en el mismo espacio marítimo. La zona económica exclusiva está vinculada a la columna de agua y a los recursos biológicos, mientras que la plataforma continental se refiere al suelo marítimo, subsuelo y recursos minerales. A pesar de la proclamación de los recursos naturales oceánicos como "herencia común de la humanidad" (artículo 136 de la Convención, prevista también, anteriormente, en el artículo 29 de la Carta de los Derechos y Deberes Económicos de los Estados), esta concepción, según Nico Schrijver, no es incompatible con la soberanía permanente de los Estados sobre los recursos naturales. En su opinión, ambos principios forman parte del mismo movimiento de fortalecimiento de la posición estratégica de los países periféricos por el derecho internacional, reaccionando a la explotación de sus recursos por otros Estados y compañías multinacionales. Los dos principios buscan promover la redistribución de la riqueza global de modo que sean factibles las estrategias nacionales de desarrollo $0^{50}$.

En el caso brasileño, fue editado el Decreto no 28.840, de 8 de noviembre de 1950, que declara la plataforma continental brasileña como dominio exclusivo de la Unión. La soberanía brasileña sobre el mar territorial fue, inclusive, manifestada por el Decreto-Ley $n^{\circ}$ 553, de 25 de abril de 1969, que atribuia al mar territorial brasileño el límite de 12 millas, posteriormente ampliado para 200 millas por el Decreto-Ley no 1.098, de 25 de marzo de 197051. La Constitución de 1988 incluyó expresamente los recursos naturales de la plataforma continental y de la zona económica exclusiva y el mar territorial como bienes de la Unión (artículo 20, Vy VI). Según Maria Inês Chaves de Andrade, la Constitución adoptó los criterios de la Convención de las Naciones Unidas sobre el Derecho del Mar, de 1982, ratificada el 22

49 SERRA (2007) pp. 79-85; DE OLIVEIRA \& RIBEIRO (2009) pp. 28-33 e 37.

50 MAROTTA (1985) pp. 290-295, 308-311 y 320-324; SCHRIJVER (2008) pp. 202-229.

51 ALBUQUERQUE (1965) p. 63; MAROTTA (1970) pp. 41 y 84-92; CHAVES (1965) pp. 110-117. 
de diciembre de 1988. La Ley no 8.617, de 04 de enero de 1993, revé la demarcación del límite de 200 millas para el mar territorial brasileño, pero reafirma la soberanía nacional para la explotación y aprovechamiento de los recursos naturales de la plataforma continental y de la zona económica exclusiva ${ }^{52}$.

Los royalties del petróleo, sin embrago, no pueden ser comprendidos como una compensación por la explotación de recursos minerales en los territorios de los Estados, Distrito Federal y Municipios. Pues, si fuesen una compensación, la distribución de los recursos recaudados no tendría el menor sentido para el caso de la explotación de petróleo y gas natural en la plataforma continental, en la zona económica exclusiva o en el mar territorial, cuyos recursos naturales pertenecen a la Unión (artículo 20, V y VI de la Constitución) ${ }^{53}$.

El texto del artículo $20, \$ 1^{\circ}$ de la Constitución busca garantizar la participación en el resultado de la explotación de petróleo o gas natural o en la compensación financiera por esa explotación. Los beneficiarios son los Estados, el Distrito Federal, los Municipios y órganos de la Administración Directa de la Unión. El texto, también, determina que los Estados, Distrito Federal y Municipios participen de los resultados o sean compensados por la explotación en su respectivo territorio. La mención a la explotación en la plataforma continental, mar territorial o zona económica exclusiva se refiere a la participación en el resultado de la explotación de los órganos de la Administración Directa de la Unión. Los órganos de la Administración Directa de la Unión no pueden recibir compensación financiera por la explotación de petróleo y gas natural porque no poseen territorio en virtud del cual necesiten ser compensados. Estos órganos solo pueden participar de los resultados en las situaciones en que la explotación se realiza en dominio federal, como la plataforma continental, mar territorial y zona económica exclusiva. Del mismo modo, los Estados, Distrito Federal y Municipios participan de la explotación o reciben compensación financiera en virtud de esta explotación ocurrir en sus respectivos territorios. No hay razón para que algunos Estados y Municipios reciban recursos en virtud de la participación en la explotación o de la compensación financiera por la explotación que ocurre sobre un dominio que no es suyo, sino de la Unión. Si el artículo 20, $\S 1^{\circ}$ de la Constitución fuese interpretado en el sentido de que los Estados, Distrito Federal y Municipios tienen derecho a recibir recursos en virtud de la participación en la explotación o de la compensación financiera por la explotación de petróleo y gas natural en dominio de la Unión, la única alternativa constitucionalmente adecuada, en virtud de los artículos $3^{\circ}$, III y 170, VII de la Constitución de 1988, que determinan la reducción de las desigualdades regionales como objetivo de la República y principio conformador del orden económico ${ }^{54}$, es la repartición de estos recursos entre todos los entes de la Federación, y no privilegiar apenas a los que se sitúan geográficamente más próximos de las reservas petroliferas.

Brasil, en su proceso de formación económica, siempre osciló entre dos grandes tendencias y los descubrimientos del pre-sal pueden conducir al pais tanto en una como en 
otra dirección. Una, es la constitución de un sistema económico nacional, autónomo, como los centros de decisión económica internalizados y basados en la expansión del mercado interno, en un proceso de desarrollo vinculado a reformas estructurales. La otra consiste en el modelo dependiente o asociado, con preponderancia de las empresas multinacionales y del sistema financiero internacional, dependiente financiera y tecnológicamente, y vinculado a las oscilaciones externas de la economía mundial ${ }^{55}$.

La constitución de un sistema económico nacional autónomo, nacionalmente integrado y fundado en la expansión del mercado interno por medio de la industrialización no es una vía de desarrollo consolidada en Brasil. Intereses económicos y políticos, internos y externos, extremamente poderosos, aún sueñan y luchan por transformar el pais en una gran plataforma de explotación de productos primarios, agrícolas y minerales, buscando de ciclo en ciclo una mejor inserción en el mercado internacional. La buena o mala utilización de los recursos petrolíferos descubiertos en la camada del pre-sal es decisiva en este embate $y$, si fuéramos a llevar en consideración el resultado contrario al interés nacional del primer remate realizado, el 21 de octubre de 2013, con la entrega de la explotación del Campo de Libra para empresas multinacionales extranjeras, como las petroleras Shell, Total e las estatales chinas CNPC (China National Petroleum Corporation) y CNOOC (China National Offshore Oil Corporation), Brasil parece estar caminando no en sentido favorable a la superación del subdesarrollo y de la soberanía energética, sino para la repetición, en el siglo XXI, de la "procesión de los milagros", descripta por Sergio Buarque de Holanda: "Tuvimos también nuestros momentos de grande riqueza. El de las minas, ciertamente, pero también el del azúcar, el del tabaco, de tantos otros géneros agrícolas, que se extraen de la tierra fértil, mientras sea fértil, como el oro se extrae, hasta que se agota, de la grava, sin retribución de beneficios. La procesión de los milagros ha de continuar así a través de todo el periodo colonial, y no interrumpirá la dependencia, ni siquiera, o la República"56.

\section{REFERENCIAS BIBLIOGRÁFICAS}

ALBINO DE SOUZA, Washington (2002): Teoria da Constituição Econômica (Belo Horizonte, Del Rey).

AlbuQUeRQue MELLO, Celso D. (1965): Plataforma Continental: Principais Aspectos (Rio de Janeiro, Livraria Freitas Bastos).

BADURA, Peter (1963): Das Verwaltungsmonopol (Berlin, Duncker \& Humblot).

BANDEIRA DE MELLO, Celso Antônio (2006): Curso de Direito Administrativo (São Paulo, Malheiros, 20a edición).

BARROSO, Luis Roberto (2002): "Modalidades de Intervenção do Estado na Ordem Econômica. Regime Jurídico das Sociedades de Economia Mista. Inocorrência de Abuso de Poder Econômico" en Temas de Direito Constitucional (Rio de Janeiro, Renovar) tomo I, pp. 389-457. 
BERCOVICl, Gilberto (2003): Desigualdades Regionais, Estado e Constituição (São Paulo, Max Limonad).

BERCOVICl, Gilberto (2011): Direito Econômico do Petróleo e dos Recursos Minerais (São Paulo, Quartier Latin).

BERNAL, Federico (2005): Petróleo, Estado y Soberanía: Hacia la Empresa Multiestatal Latinoamericana de Hidrocarburos (Buenos Aires, Editorial Biblos).

BUARQUE DE HOLANDA, Sergio (1992): Visão do Paraiso: Os Motivos Edênicos no Descobrimento e Colonização do Brasil (São Paulo, Brasiliense, $5^{a}$ edición).

BUCHEB, José Alberto (2007): Direito do Petróleo: A Regulação das Atividades de Exploração e Produção de Petróleo e Gás Natural no Brasil (Rio de Janeiro, Lumen Juris).

CHAVES DE ANDRADE, Maria Inês (1965): A Plataforma Continental Brasileira. (Belo Horizonte, Del Rey).

CLĖVE, Clèmerson Merlin \& FERREIRA MARTINS (2004): "Principios Constitucionais da Atividade Econômica Petrolífera e Lei no 9.478 de 1997". A \& C - Revista de Direito Administrativo e Constitucional no 18: pp. 43-50.

CONTRERAS, Edelmira del Carmen (1994): Os Desbravadores: A Petrobrás e a Construção do Brasil Industrial (Rio de Janeiro, Relume-Dumarál ANPOCS).

COUTO MARTINS, Daniela (2006): A Regulação da Indústria do Petróleo segundo o Modelo Constitucional Brasileiro (Belo Horizonte, Fórum).

CUPERTINO, Fausto (1976): Os Contratos de Risco e a Petrobrás (O Petróleo é Nosso, o Risco é Deles?) (Rio de Janeiro, Civilização Brasileira).

DE MATTOS DIAS, José Luciano \&t QUAGLINO, Maria Ana (1993): A Questão do Petróleo no Brasil: Uma História da Petrobrás (Rio de Janeiro, Ed. FGV/Petrobrás).

DE MIRANDA FERREIRA, Antônio Luís (2005): "A Desmonopolização do Mercado" en: PIRES, Paulo Valois (edit.). Temas de Direito do Petróleo e do Gás Natural II (Rio de Janeiro, Lumen Juris) pp. 29-58.

DE MORAES, Alexandre (2001) "Regime Jurídico da Concessão para Exploração de Petróleo e Gás Natural". Revista de Direito Constitucional e Internacional no 36, pp. 162-176.

DE OLIVERA CRUZ, Bruno \&t RIBEIRO, Márcio Bruno (2009): Sobre Maldições e Bênçãos: É Possivel Gerir Recursos Naturais de Forma Sustentável? Uma Análise sobre os Royalties e as Compensações Financeiras no Brasil. Brasília: IPEA (Texto para Discussão no 1412). DUARTE PEREIRA, Osny (1988) "A Questão Mineral na Constituinte" en: GUERREIRO, Gabriel et al. Constituinte: A Nova Politica Mineral (Brasilia, CNPq) pp. 99-169.

FEROLLA, Sergio Xavier \& METRI, Paulo (2006): Nem Todo Ø Petróleo É Nosso (Rio de Janeiro, Paz e Terra).

FIOROTI CAMPOS, Adriana (2007): Indústria do Petróleo: Reestruturação Sul-Americana nos Anos 90 (Rio de Janeiro, Interciência).

GUTMAN, José \&t LEITE, Getúlio (2003): "Aspectos Legais da Distribuição Regional dos Royalties" en: PIQUET, Rosélia (edit.). Petróleo, Royalties e Região (Rio de Janeiro, Garamond) pp. 125-161.

IANNI, Octavio (1989) Estado e Capitalismo (São Paulo, Brasiliense, 2a edición). 
JOHNSTON, Daniel (1994): International Petroleum Fiscal Systems and Production Sharing Contracts (Tulsa, PennWell Books).

JOHNSTON, Daniel (2003): International Exploration Economics, Risk, and Contract Analysis. (Tulsa, PennWell Books).

JOHNSTON, David (2007) "How to Evaluate the Fiscal Terms of Oil Contracts". en: HUMPHREYS, Macartan; SACHS, Jeffrey D. \& STIGLITZ, Joseph E. (edits.). Escaping the Resource Curse (New York, Columbia University Press) pp. 53-88.

KLAPP, Merry Gilbert (1987): The Sovereign Entrepreneur: Oil Policies in Advanced and Less Developed Capitalist Countries (Ithaca/London, Cornell University Press).

KONDER COMPARATO, Fábio (1996): "Monopólio Público e Domínio Público - Exploração Indireta da Atividade Monopolista" en: Direito Público: Estudos e Pareceres (São Paulo, Saraiva) pp. 146-153.

LESSA, Carlos (2004): Auto-Estima e Desenvolvimento Social (Rio de Janeiro, Garamond, 2a edición).

LESSA, Carlos (2009) "Infraestrutura e Logística no Brasil". en: CARDOSO Jr., José Celso (edit.) Desafios ao Desenvolvimento Brasileiro: Contribuições do Conselho de Orientação do IPEA (Brasília, IPEA) vol. 1, pp. 77-100.

LIMA Neto, Procopio. "Parecer da Comissão Especial Destinada a Proferir Parecer à Proposta de Emenda à Constituição n 6, de 1995, que 'Altera o $\$ 1^{\circ}$ do Art. 177' (Monopólio do Petróleo)". Diário do Congresso Nacional, Seção I, Sábado, 20 de Maio de 1995, pp. 10638-10644.

MACHMUD, Tengko Nathan (2000): The Indonesian Production Sharing Contract:An Investor's Perspective (Dordrecht/Cambridge (Ma.), Kluwer Law International).

MAROTTA RANGEL, Vicente (1970): Natureza Jurídica e Delimitação do Mar Territorial (São Paulo, RT, 2a edición).

MAROTTA RANGEL, Vicente (1985): Le Plateau Continental dans la Convention de 1982 sur le Droit de la Mer en: Recueil des Cours de l'Académie de Droit International de La Haye (Dordrecht, Martinus Nijhoff) tomo 194, pp. 271-427.

McPHERSON, Charles (2003) "National Oil Companies: Evolution, Issues, Outlook". en: DAVIS, Jeffrey M.; OSSOWSKI, Rolando \&t FEDELINO, Annalisa (edit.). Fiscal Policy Formulation and Implementation in Oil-Producing Countries. (Washington, International Monetary Fund) pp. 184-203.

MENDEZ DE BRITO, Raimundo (1996): "Flexibilizar Significa Desenvolver" en IBP \& FGV (orgs.). A Nova Regulamentação da Indústria de Petróleo no Brasil. (Rio de Janeiro, FGV) pp. 7-15. MUGHRABY, Muhamad A. (1996): Permanent Sovereignty Over Oil Resources: A Study of Middle East Oil Concessions and Legal Change (Beirut, The Middle East Research and Publishing Center).

NORENG, øysten (1980): The Oil Industry and Government Strategy in the North Sea. (London/ Boulder, Croom Helm/The International Research Center for Energy and Economic Development). 
PEREZ ALFONZO, Juan Pablo (1967): El Pentágono Petrolero (Caracas, Ediciones Revista Política).

PILATTI, Adriano (2008) A Constituinte de 1987-1988: Progressistas, Conservadores, Ordem Econômica e Regras do Jogo (Rio de Janeiro, Ed. PUC-Rio/Lumen Juris).

RIBEIRO, Nelson de F (1989): "As Macroperspectivas do Direito Minerário a partir da Nova Constituição". Revista de Informação Legislativa no 102: pp. 69-76.

RUY BARBOSA, Alfredo (2005): "A Natureza Jurídica da Concessão para Exploração de Petróleo e Gás Natural" en: PIRES, Paulo Valois (edit.), Temas de Direito do Petróleo e do Gás Natural II. (Rio de Janeiro, Lumen Juris) pp. 1-28.

SANTOS DE ARAGÃO, Alexandre (2005): "0 Contrato de Concessão de Exploração de Petróleo e Gás", Revista de Direito Administrativo n 239, pp. 411-438.

SCHRIJVER, Nico (2008): Sovereignty Over Natural Resources: Balancing Rights and Duties (Cambridge/New York, Cambridge University Press, reimpr.).

SERRA, Rodrigo \& PATRÃO, Carla (2003): "Impropriedades dos Critérios de Distribuição dos Royalties no Brasil" en: PIQUET, Rosélia (edit.). Petróleo, Royalties e Região (Rio de Janeiro, Garamond) pp. 185-216.

SERRA, Rodrigo (2007): "Concentração Espacial das Rendas Petroliferas e Sobrefinanciamento das Esferas de Governo Locais" en: PIQUET, Rosélia \& SERRA, Rodrigo (edit.) Petróleo e Região no Brasil: O Desafio da Abundância (Rio de Janeiro, Garamond) pp. 77-110.

TÁCITO, Caio (1997): "Regime Federativo. Lei Estadual. Gás Liquefeito de Petróleo" en: Temas de Direito Público (Estudos e Pareceres) (Rio de Janeiro, Renovar) vol. 2, pp. 1123-1132.

TAVARES, Maria da Conceição (1999): Destruição Não Criadora: Memórias de um Mandato Popular contra a Recessão, o Desemprego e a Globalização Subordinada (Rio de Janeiro, Record).

VALOIS, Paulo (2000): A Evolução do Monopólio Estatal do Petróleo (Rio de Janeiro, Lumen Juris).

VILLAS-BÔAS, Ana Lucia (1995): Mineração e Desenvolvimento Econômico: A Questão Nacional nas Estratégias de Desenvolvimento do Setor Mineral (1930-1964) (Rio de Janeiro, CNPq/CETEM, 2 vols).

ZANELLA DI PIETRO, Maria Sylvia (2010): Uso Privativo de Bem Público por Particular. (São Paulo, Atlas, 2a edición).

\section{Normas Citadas}

Constitución Federal Brasilera.

Convención de las Naciones Unidas sobre el Derecho del Mar de 1982.

Decreto no 28.840 de 8 de noviembre de 1950.

Decreto no 49.331 de 24 de noviembre de 1960.

Decreto-Ley no 553 de 25 de abril de 1969.

Decreto-Ley no 1.098 de 25 de marzo de 1970.

Decreto no 99.244 de 10 de mayo de 1990.

Decreto no 99.432 de 31 de julio de 1990. 
Decreto $n^{\circ} 2.926$ de 7 de enero de 1999.

Decreto $n^{\circ} 5.267$ de 09 de noviembre de 2004.

Ley no 2.004 de 3 de octubre 1953.

Ley no 8.617 de 04 de enero de 1993.

Ley no 9.478 de 6 de agosto de 1997.

Ley no 9.847 de 26 de octubre de 1999.

Ley no 12.351 de 22 de diciembre de 2010.

Ley n० 12.380 de 10 de enero 2011.

Ley no 12.734, de 30 de noviembre de 2012.

Medida Provisoria n 500 de 30 de agosto de 2010. 